\title{
Determining Eight Biogenic Amines in Surface Water Using High-Performance Liquid Chromatography-Tandem Mass Spectrometry
}

\author{
Zhengtao Quan ${ }^{1}$, Guangfa Xie ${ }^{2}$, Qi Peng ${ }^{1 *}$, Jicheng Shan ${ }^{1}$, Wenhao Xing ${ }^{1}$, \\ Jialei Zhang ${ }^{1}$, Shiling Li ${ }^{1}$, Zhongyu Chan ${ }^{1}$, Chuanfeng Chou ${ }^{1}$, HuiJun Zou ${ }^{2}$ \\ ${ }^{1}$ School of Life Sciences, Shaoxing University, Shaoxing, 312000 China \\ ${ }^{2}$ National Engineering Research Center for Chinese Rice Wine, China Shaoxing Rice Wine Group Co., Ltd, \\ Shaoxing 312000, China
}

Received: 26 November 2015

Accepted: 7 March 2016

\begin{abstract}
A method for determining eight biogenic amines in surface water was established using high-performance liquid chromatography-triple quadrupole mass spectrometry to improve on the detection sensitivity of current methods. The limits of detection and quantification were 0.05 and $0.2 \mu \mathrm{g} \mathrm{L}^{-1}$, respectively, for histamine, cadaverine, spermine, and spermidine, 1.0 and $3.0 \mu \mathrm{g} \mathrm{L} \mathrm{L}^{-1}$, respectively, for putrescine, 1.5 and $5.0 \mu \mathrm{g} \mathrm{L}^{-1}$, respectively, for tyramine and tryptamine, and 2.0 and $5.0 \mu \mathrm{g} \mathrm{\textrm {L } ^ { - 1 }}$, respectively, for 2-phenylethylamine. The recovery of biogenic amines from spiked water samples was between 97.3 and $108.6 \%$ at levels between 0.05 and $15 \mu \mathrm{g} \mathrm{L}^{-1}(R>0.999)$. The relative standard deviations were in the range of $0.10-0.29 \%$. This method can achieve rapid and accurate determination of biogenic amines in surface water, and it meets the minimum residue measurement requirements.
\end{abstract}

Keywords: HPLC-MS/MS, surface water, biogenic amines

\section{Introduction}

Biogenic amine (BA) is the generic name for lowmolecular-weight nitrogen-containing organic compounds. BAs are not only precursors in the synthesis of hormones, nucleic acids, proteins, and so on, but also precursors of carcinogens and nitroso compounds $[1,2]$. Trace BAs are normal biologically active components in living bodies, including the human body. They have important physiological functions in cells, but become toxic when accumulated in high levels in the human body. Putrescine

*e-mail: mike.peng@126.com
(PUT), cadaverine (CAD), 2-phenylethyleamine (2-PHE), tyramine (TYR), and tryptamine (TRP) are common BAs as well as highly toxic, water-soluble chemicals. After the death of an organism, bacterial decomposition of the body produces a certain amount of BAs, which can cause water pollution [1].

In 2008 the China State Bureau of Quality and Technical Supervision issued a standard high-performance liquid chromatography (HPLC) method for determining PUT, CAD, spermidine (SPD), spermine (SPM), and histamine (HIS) in water samples [3]. However, this standard method using pre-column derivatization HPLC has a number of drawbacks, including multi-step extraction, the formation of multiple derivatives, a time-consuming process, low 
detection sensitivity (in the range $2.0-40.0 \mathrm{mg} \mathrm{L}^{-1}$ ), and false positive result [3-5]. To date, only HPLC methods have been reported for the detection of BAs in water.

In view of this, this study used HPLC as the separation system and triple quadrupole mass spectrometry as the detection system. High-performance liquid chromatography (HPLC) is good for separation of complex samples. Relative molecular mass and structural information can be provided by mass spectrometry of high selectivity and high sensitivity. By combining advantages of chromatogram and mass spectrum, we directly determined eight BAs in surface water without the formation of derivatives.

\section{Materials and Methods}

\section{Materials}

Ammonium acetate was purchased from Hangzhou Chemical Reagent Co. Ltd., and HIS, CAD, SPM, SPD, PUT, TYR, TRP, 2-PHE, and HPLC-grade methanol were purchased from Sigma, USA. Formic acid and organic phase filtration membranes were obtained from the Alfa Aesar A Johnson Matthey Company. Water was purified using a Milli-Q ultrapure water purification system (Millipore Co., Germany).

\section{Instrumentation}

The HPLC-MS/MS system consisted of an Agilent 1290 Series liquid chromatograph (with a line degasser and autosampler) and an Agilent 6460 triple quadrupole mass spectrometer (Agilent Technologies, Inc., USA) with electrospray ionization (ESI).

Separation of the BAs was performed on a hydrophilic interaction chromatography column $(50 \mathrm{~mm} \times 2.1 \mathrm{~mm}$, $2.6 \mu \mathrm{m}$, Agilent Technologies). The mobile phase was $5 \mathrm{mmol} \mathrm{L}-1$ aqueous ammonium acetate and methanol (6:4 by volume). The mobile phase flow rate was $0.2 \mathrm{~mL} \mathrm{~min}^{-1}$, the sample injection volume was $5 \mu \mathrm{L}$, and the column temperature was $30^{\circ} \mathrm{C}[6,7]$.

For MS, the ESI conditions were as follows: gas temperature $350^{\circ} \mathrm{C}$, gas flow rate $11 \mathrm{~L}^{-1} \mathrm{~min}$, nebulizer $50 \mathrm{psi}$, capillary voltage $4000 \mathrm{~V}$ (positive) and $3500 \mathrm{~V}$ (positive), sheath gas temperature $100^{\circ} \mathrm{C}$, nozzle voltage $500 \mathrm{~V}[8]$.

\section{Sample Preparation}

MCX Solid phase extraction column was conditioned by passing $2 \mathrm{~mL}$ of methanol followed by $2 \mathrm{~mL}$ of Milli-Q purified water. $10 \mathrm{ml}$ Surface water samples were filtered through 0.45 micron disposable filters. The filtrate was added to an MCX solid phase extraction column. And then $2 \mathrm{~mL} \mathrm{3 \%}$ (by volume) formic acid aqueous solution was run through the column and the effluent discarded (The

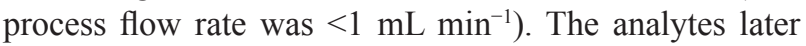
were eluted with $3 \mathrm{~mL}$ of $3 \%$ ammonia methanol solution (the process flow rate was $<1 \mathrm{~mL} \mathrm{~min}{ }^{-1}$ ). The eluate was collected in a vial. Eluate was then gently dried by blowing nitrogen for $20 \mathrm{~min}$; methanol was added to $1 \mathrm{~mL}$ in the vial and the analytes were filtered through $0.22 \mu \mathrm{m}$ filter into vials for test $[9,10]$.

\section{Results and Discussion}

\section{Optimization of Ion Detection Conditions}

The selected ion monitoring mode in HPLC-MS/MS was used to optimize the conditions for determining BAs.

First, we used the SIM mode to determine the retention time of the Bas and confirm the mass number of the target compound precursor ions. Second, we optimized the capillary outlet voltage (fragmentor) to ensure transmission efficiency of the parent ion. Then we made the daughter ion scan to get optimal response of product ions by using optimized capillary outlet voltage to choose a quantitative ion and optimization collision energy [11]. Multiple reaction mode (MRM) quantitative analysis was conducted using the optimized capillary outlet voltage and collision energy [12]. The ESI positive ion mode was used to qualitatively and quantitatively determine the eight BA ions. The optimized MRM conditions are shown in Table 1.

\section{Linear Relationship and Detection Limit}

Standard working solutions for the eight BAs at concentrations ranging from 0.05 to $15 \mu \mathrm{g} \mathrm{L}^{-1}$ were used to determine the linear relationship between ion peak area and BA concentration and detection limit. MRM mass spectrograms of the BAs in surface water are shown in Fig. 1. Final test results were negative for surface water blank BAs after adding the mixed standard separation of the eight BAs on the chromatogram was determined to be good. There was no interference from miscellaneous peaks. To quantitatively determine the linear relationship for each BA, the ion peak area was plotted as the vertical axis and the BA concentration was plotted as the horizontal axis to obtain the linear regression equation. There was a good linear relationship between BA concentration and the quantitative ions. Limit of detection (LOD) and limit of quantification (LOQ) were measured based on signal-to-noise ratios of about 3 and 10, respectively. The fitted linear regression equations are shown in Table 2. The correlation coefficients of the standard curves were $\geq 0.9990$, reflecting good correlation. HPLC-MS/ MS detection of BAs compared with HPLC with a lower detection limit.

\section{Precision and Recovery}

Recovery was determined using the standard addition recovery test. Three concentrations of BA standards were added to surface water samples: 1,3 , and $5 \mu \mathrm{g} \mathrm{L}^{-1}$. The recovery studies were repeated three times and the 
Table 1. Detection conditions of eight biogenic amines using MRM mode.

\begin{tabular}{|c|c|c|c|c|c|c|}
\hline BA & $\begin{array}{l}\text { Precursor Ion } \\
\quad(\mathrm{m} / \mathrm{z})\end{array}$ & Product Ion $(\mathrm{m} / \mathrm{z})$ & Dwell (s) & $\begin{array}{l}\text { Fragmentor } \\
\text { (v) }\end{array}$ & $\begin{array}{l}\text { Collision Energy } \\
\text { (v) }\end{array}$ & $\begin{array}{c}\text { Cell Accelerator } \\
\text { Voltage (v) }\end{array}$ \\
\hline \multirow{2}{*}{ Histamine } & \multirow{2}{*}{112.2} & 95.0 & 50 & 80 & 13 & 7 \\
\hline & & 68.1 & 50 & 80 & 21 & 7 \\
\hline \multirow{2}{*}{ Cadaverine } & \multirow{2}{*}{102.2} & 58.1 & 50 & 80 & 21 & 7 \\
\hline & & 43.1 & 50 & 80 & 13 & 7 \\
\hline \multirow[b]{2}{*}{ Putrescine } & \multirow{2}{*}{89.2} & 72.1 & 50 & 85 & 5 & 7 \\
\hline & & 30.0 & 50 & 85 & 21 & 7 \\
\hline \multirow{2}{*}{ Spermine } & \multirow{2}{*}{203.2} & 129.1 & 50 & 320 & 9 & 7 \\
\hline & & 84.1 & 50 & 320 & 35 & 7 \\
\hline \multirow{2}{*}{ Spermidine } & \multirow{2}{*}{146.3} & 112.1 & 50 & 320 & 13 & 7 \\
\hline & & 72.1 & 50 & 320 & 13 & 7 \\
\hline \multirow{2}{*}{ 2-phenylethylamine } & \multirow{2}{*}{122.2} & 105.0 & 50 & 70 & 9 & 7 \\
\hline & & 77.0 & 50 & 70 & 33 & 7 \\
\hline \multirow{2}{*}{ Tyramine } & \multirow{2}{*}{138.2} & 121.0 & 50 & 80 & 5 & 7 \\
\hline & & 77.0 & 50 & 80 & 33 & 7 \\
\hline \multirow[b]{2}{*}{ Tryptamine } & \multirow{2}{*}{161.2} & 144.0 & 50 & 80 & 9 & 7 \\
\hline & & 117.0 & 50 & 80 & 35 & 7 \\
\hline
\end{tabular}

recovery mean was calculated. The results are shown in Table 3. The recoveries of the eight BAs in the surface water matrices were between 97.3 and $108.6 \%$, and the relative standard deviations (RSDs) were between 0.10 and $0.29 \%$. The percentage recoveries and RSDs obtained using this method meet the minimum requirements for residue analysis.

\section{Surface Water Sample Test}

Under the HPLC-MS/MS experimental conditions, blank samples of surface water were added to $15 \mu \mathrm{g} \mathrm{L}^{-1}$ of standard working solution. Ion chromatogram peak of the eight kinds of BAs in the spiked sample does show a good peak shape. All peaks have good symmetry: HIS
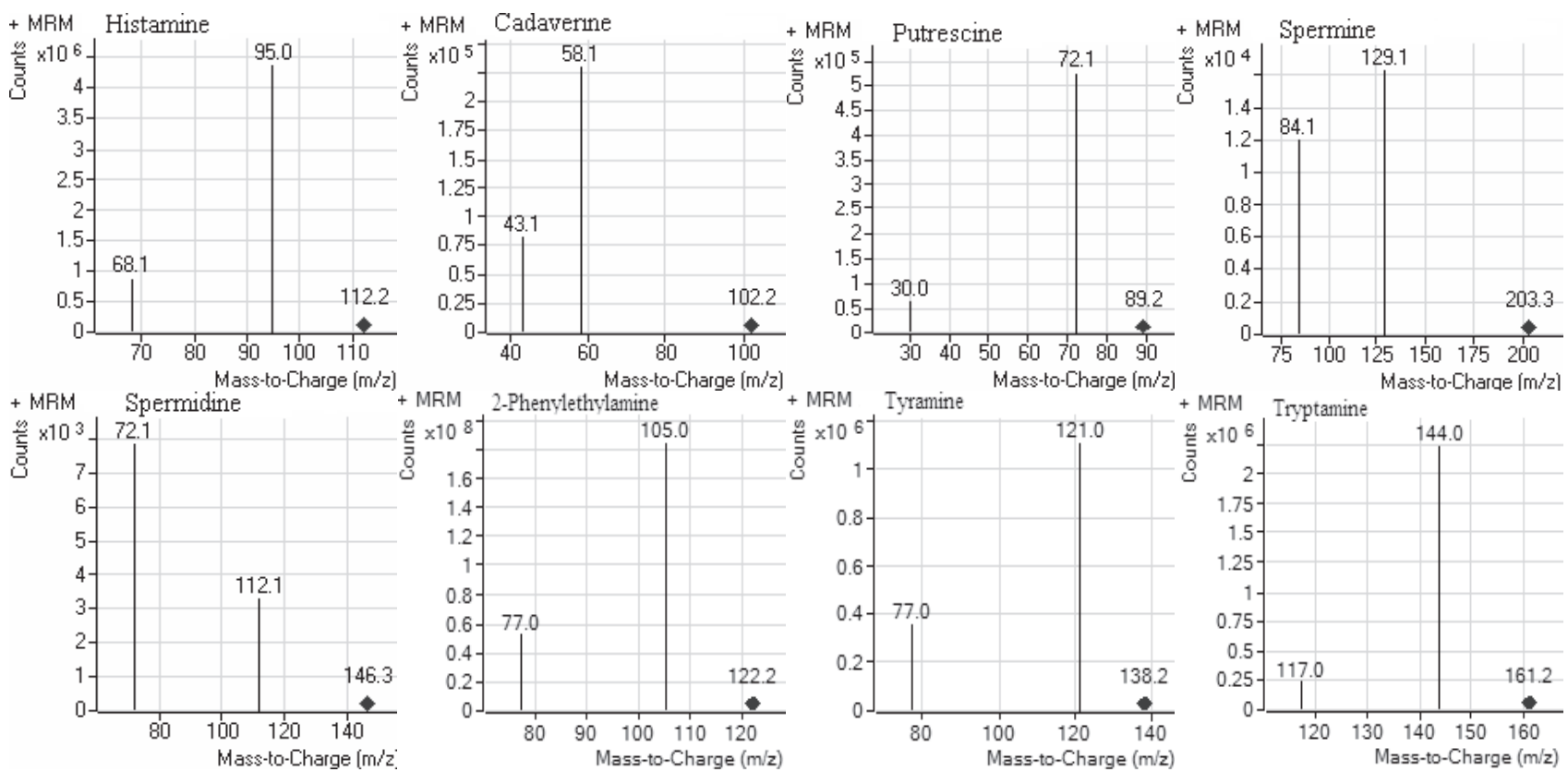

Fig. 1. MRM mass spectrogram of biogenic amines in surface water. 
Table 2. Linear relationships, LODs, and LOQs for the eight biogenic amines.

\begin{tabular}{|c|c|c|c|c|c|}
\hline BA & Linear range $(\mu \mathrm{g} / \mathrm{L})$ & linear equation & $\mathrm{r}^{2}$ & $\mathrm{LOD}(\mu \mathrm{g} / \mathrm{L})$ & $\mathrm{LOQ}(\mu \mathrm{g} / \mathrm{L})$ \\
\hline Histamine & $0.05-15$ & $\mathrm{Y}=3609.21 \mathrm{X}+19691$ & 0.9990 & 0.05 & 0.2 \\
\hline Cadaverine & $0.05-15$ & $\mathrm{Y}=1985.61 \mathrm{X}+4385$ & 0.9991 & 0.05 & 0.2 \\
\hline Putrescine & $0.05-15$ & $\mathrm{Y}=1506.28+2066$ & 0.9995 & 1.0 & 3.0 \\
\hline Spermine & $0.05-15$ & $\mathrm{Y}=216.70 \mathrm{X}+151$ & 0.9992 & 0.05 & 0.2 \\
\hline Spermidine & $0.05-15$ & $\mathrm{Y}=87.69 \mathrm{X}+181$ & 0.9996 & 0.05 & 0.2 \\
\hline 2-phenylethylamine & $0.05-15$ & $\mathrm{Y}=82019.07 \mathrm{X}+188077$ & 0.9991 & 2.0 & 5.0 \\
\hline Tyramine & $0.05-15$ & $\mathrm{Y}=6430.10 \mathrm{X}+22160$ & 0.9990 & 1.5 & 5.0 \\
\hline Tryptamine & $0.05-15$ & $\mathrm{Y}=5159.23 \mathrm{X}+30809$ & 0.9995 & 1.5 & 5.0 \\
\hline
\end{tabular}

parent ion 112.2, qualitative and quantitative ions 68.1 and 95.0; CAD parent ion 102.2, qualitative and quantitative ions 43.1 and 58.1; PUT parent ion 89.2, qualitative and

Table 3. Spike recovery tests $(n=6)$.

\begin{tabular}{|c|c|c|c|}
\hline BA & $\begin{array}{c}\text { Spiked } \\
\text { level } \\
(\mu \mathrm{g} / \mathrm{kg})\end{array}$ & $\begin{array}{c}\text { Recovery } \\
\text { mean } \\
(\%)\end{array}$ & $\begin{array}{l}\text { Repeatability } \\
\text { (RSD, \%) }\end{array}$ \\
\hline \multirow{3}{*}{ Histamine } & 1 & 98.9 & 0.29 \\
\hline & 3 & 105.5 & 0.21 \\
\hline & 5 & 103.7 & 0.17 \\
\hline \multirow{3}{*}{ Cadaverine } & 1 & 97.0 & 0.16 \\
\hline & 3 & 99.6 & 0.19 \\
\hline & 5 & 101.1 & 0.15 \\
\hline \multirow{3}{*}{ Putrescine } & 1 & 99.2 & 0.22 \\
\hline & 3 & 99.1 & 0.27 \\
\hline & 5 & 103.9 & 0.25 \\
\hline \multirow{3}{*}{ Spermine } & 1 & 97.4 & 0.12 \\
\hline & 3 & 99.6 & 0.26 \\
\hline & 5 & 97.3 & 0.28 \\
\hline \multirow{3}{*}{ Spermidine } & 1 & 94.3 & 0.29 \\
\hline & 3 & 105.1 & 0.25 \\
\hline & 5 & 108.6 & 0.27 \\
\hline \multirow{3}{*}{ 2-phenylethylamine } & 1 & 105.8 & 0.13 \\
\hline & 3 & 106.6 & 0.10 \\
\hline & 5 & 107.1 & 0.27 \\
\hline \multirow{3}{*}{ Tyramine } & 1 & 104.3 & 0.18 \\
\hline & 3 & 106.5 & 0.21 \\
\hline & 5 & 108.3 & 0.19 \\
\hline \multirow{3}{*}{ Tryptamine } & 1 & 106.3 & 0.23 \\
\hline & 3 & 107.5 & 0.26 \\
\hline & 5 & 108.3 & 0.19 \\
\hline
\end{tabular}

quantitative ions 30.0 and 72.1; SPM parent ion 203.2, qualitative and quantitative ions 84.1 and 129.1; SPD precursor ion 146.3, qualitative and quantitative ions 112.1 and 72.1 ; 2-PHE parent ion 122.2, qualitative and quantitative ions 77.0 and 105.0; TYR parent ion 138.2, qualitative and quantitative ions 77.0 and 121.0; TRP precursor ion 161.2, qualitative and quantitative ions pair 117.0 and 68.1 [13-17]. We used MS is the triple quadruple (QQQ) mass spectrometer because of its capability to run a large variety of different experiments. The QQQ instrument is comprised of three quadrupoles arranged in a linear row, where the first (Q1) and third (Q3) act as mass filters and the quadrupole in the middle (Q2) acts as a collision cell for molecular fragmentation and generation of MS/MS information. Product ion scan, where Q1 acts as a mass filter to selectively isolate a single $\mathrm{m} / \mathrm{z}$, which is fragmented in Q2. The fragments are scanned in Q3 for the generation of a fragment mass spectrum. This scan mode creates an MS/MS spectrum for the precursor ion selected by Q1 [18-21].

\section{Conclusions}

This was an experimental study on the use of HPLCMS/MS as a rapid detection method for determining BAs in surface water samples. The sample pretreatment for LC-MS is quick and easy. Other methods for determining BAs were excluded because of false positives [22]. The standard addition recovery test showed that HPLC-MS/ MS has higher sensitivity and a detection limit down to lower level compared with the current conventional liquid phase standard procedure.

1. The HPLC-MS/MS method can achieve accurate qualitative and quantitative information about trace BAs in surface water samples without using the derivatization process. This improves the efficiency for testing large quantities of samples before treatment, while addressing the false positive problem. It meets the residue testing requirements of BAs in surface water samples.

2. With the HPLC-MS/MS method, if the measured result is outside the linear range of the method, the sample solution can be diluted to within the linear range 
[23]. As the method uses ESI, when the concentration of the sample solution is too high, the ion abundance ratio exceeds the standard abundance ratio range due to the ion suppression phenomenon. Therefore, for this method to be suitable for the accurate qualitative and quantitative determination of the actual concentrations of trace BAs, high-concentration samples should be diluted before injection to obtain good detection results.

\section{Acknowledgements}

We thank financial support provided by Shaoxing University Foundation (No. 20145031) and Xinmiao Talents Program in Zhejiang province (No. 2016R428024).

\section{References}

1. ZHANG F.J., XUE J., et al. Dynamic changes of the content of biogenic amines in Chinese rice wine during the brewing process. Journal of the Institute of Brewing 119, 294, 2013.

2. ZHANG F.J., XUE J., WANG Y.J., et al. Study on biogenic amines formation and influencing factors in Chinese rice wine. Journal of Food Fermentation Industrial 39 (02), 65, 2013.

3. GB/T 21970-2008, Water Quality-Determination of Putrescine, Cadaverine, Spermidine, Spermine and Histamine-High Performance Liquid Chromatography Method. S.

4. LI Z.J., WU Y.N., XUE C.H. Effects of Biogenic Amines on Food Safety and Human Health. Journal of Food Fermentation Industrial 30 (10), 90, 2004.

5. ZHANG J., ZHAO S.X., XUE J., et al. Investigation and Analysis of the Content of Biogenic Amines in Fermented Alcoholic Beverage. Journal of Analytica Test 38 (6), 165 , 2012.

6. QIAO C.D., SONG P.S., YAN X., JIANG S.X. Separation of Biogenic Amines by Micellar Electrokinetic Chromatography. Journal of Analysis Chemistry 35 (1), 95, 2007.

7. YU L., XIE J.Y., LAN J.F. Determination of biogenic amines in surface water. Journal of Agricultural Science 40 (11), 6498, 2012.

8. PENG Q., SHOU Q., GE L.Y., et al. Comparative study of the detection of sodium cyclamate in yellow rice wine by HPLC. Journal of Liquor-Making Science Technology 223 (01), 19, 2013.

9. CHENG X.Y., YANG Q.H., LEI E.R., et al. Determination of five biogenic amines in surface water by HPLC-MS/MS. Journal of Sichuan Environment 30 (1), 35, 2011.
10. WANG Y., QIU F., ZHONG B.Z., et al. Biogenic amines in food and their determination methods. Journal of China Brewing 235 (10), 1, 2011.

11. VINCI G., ANTONELLI M.L. Biogenic amines: quality index of freshness in red and white meat. Journal of Food Control 13, 519, 2002.

12. MORET S., SMELA D., POPULIN T., et al. A survey on free biogenic amine content of fresh and preserved vegetables. Journal of Food Chemistry 89, 355, 2005.

13. CAPOZZI V., RUSSO P., LADERO V., FERNÁNDEZ M., FIOCCO D., ALVAREZ M.A., et al. Biogenic amines degradation by Lactobacillus plantarum: toward a potential application in wine. Frontiers in Microbiology 3, 122, 2012.

14. LINARES D.M., DEL RÍO B., LADERO V., MARTÍNEZ N., FERNÁNDEZ M., MARTÍN M.C., et al. Factors influencing biogenic amines accumulation in dairy products. Frontiers in Microbiology 3, 180, 2012.

15. VISCIANO P., SCHIRONE M., TOFALO R., SUZZI G. Biogenic amines in raw and processed seafood. Frontiers in Microbiology 3, 188, 2012.

16. SMIT A.Y., ENGELBRECHT L., DU TOIT M. Managing your wine fermentation to reduce the risk of biogenic amine formation. Frontiers in Microbiology 3, 76, 2012.

17. VISCIANO P., SCHIRONE M., TOFALO R., SUZZI G. Histamine poisoning and control measures in fish and fishery products. Frontiers in Microbiology 5, 500, 2014.

18. GUNTHER S., CHRISTIAN W., HUCK M., et al. Determination of flavonoids and stilbenes in red wine and related biological products by HPLC and HPLC-ESI-MSMS. Journal of Analysis Chemistry 371 (1), 73, 2001.

19. SARNECKIS C.J., DAMBERGS R.G., JONES P., et al. Quantification of condensed tannins by precipitation with methyl cellulose: development and validation of an optimized tool for grape and wine analysis. Australian Journal of Grape and Wine Research 12 (1), 39, 2006.

20. YARU S., JOSEPH L. Enhancing capillary liquid chromatography / tandem mass spectrometry of biogenic amines by pre-column derivatization with 7-fuloro 4-nitrobenzoxadia zole. Journal of Rapid Communications in Mass Spectrometry 18, 989, 2004.

21. GARCÍA-BENEYTEZ E., CABELLO F., REVILLA E. Analysis of Grape and Wine Anthocyanins by HPLC-MS. Journal of Agricultural and Food Chemistry 51 (19), 5622, 2003.

22. PURI A., AHMAD A., PANDA B.P. Development of an HPTLC-based diagnostic method for invasive aspergillosis. Biomedical Chromatography 24, 887, 2009.

23. PENG Q., TIAN R., LI B., et al. Determination of Luteoskyrin in Rice Wine by High-Performance Liquid Chromatography - Ion Trap Tandem Mass Spectrometry. Analytical Letters, 48 (1), 9, 2015. 